suy giảm chức năng thận [5]. Độc tính trên thận được báo cáo dao động từ $5-11 \%$ nếu sử dụng đơn độc và tăng lên đến $22 \%$ nếu phối hợp kháng sinh aminoglycoside và độc tính trên thận có thể xảy ra ở ngày điều trị thứ 5.

\section{KẾT LUẬN}

Cân có các chương trình toàn diện để cải thiện việc sử dụng vancomycin trong các bệnh viện. Việc sử dụng Vancomycin nên được theo dõi để tối ưu hóa việc sử dụng thuốc.

\section{TÀI LIÊU THAM KHẢO}

1. Bùi Thi Hương Quỳnh và Triệu Alpha (2018), "Khảo sát tình hình sử dụng vancomycin tại bệnh viện Thống Nhất thành phố Hồ Chí Minh", Tạp chí Y hoc, 1, 66-70.

2. Đặng Nguyễn Đoan Trang (2019), "Khảo sát và đánh giá hiêuu quả theo dôi nông đô vancomycin trong trị liêu tai Bênh viên Đai học Y̛ Dược thành phố hồ chí minh", Nghiến cứu dược và thông tin thuốc 2019, tập 10, số 3, trang 30-37

3. Nguyê̂n Thị Mai Anh (2019), "Phân tích thực trạng sử dụng kháng sinh vancomycin tại bệnh viện Thanh Nhàn", luân văn Thạc sĩ dược học, trường Đại học Y Hà Nội

4. Hiramatsu $\dot{k}$. Vancomycin-resistant Staphylococcus aureus: a new model of antibiotic resistance. Lancet Infect Dis 2001;1(3):147-55.

5. Linden P. K. (2007), "Optimizing therapy for vancomycin-resistant enterococci (VRE)", Semin Respir Crit Care Med. 28 (6), pp. 632-645.

6. Nimish Patel, Manjunath P. Pai, Keith A Rodvold, Ben Lomaestro, George L. Drusano, Thomas P. Lodise, Vancomycin: We Can't Get There From Here, Clinical Infectious Diseases, Volume 52 , Issue 8,15

7. Richard H Drew, George Sakoulas. Vancomycin: Parenteral dosing, monitoring and adverse effects in adults. Uptodate. Truy câp ngày 31/07/2017.

8. Rybak M, Lomaestro B, Rotschafer JC, et al. Therapeutic monitoring of vancomycin in adult patients: a consensus review of the American Society of Health-System Pharmacists, the Infectious Diseases Society of America, and the Society of Infectious Diseases Pharmacists. Am J Health Syst Pharm 2009; 66(1): 82-98.

\title{
KIẾN THỨC, THỰC HÀNH VỀ VÊ SINH AN TOÀN THỰC PHẨM CỦA NGƯỜI CHẾ BIẾN THỰC PHẨM TAI BẾP ĂN TẬP THỂ MộT Số BỆNH VIỆn TẠI HÀ NộI NĂM 2020
}

\author{
Nguyễn Thị Thu Hà ${ }^{1}$, Trịnh Bảo Ngọc ${ }^{1}$, Trần Ngọc Tụ ${ }^{2}$
}

\section{TÓM TẮT}

Một nghiên cứu cắt ngang được tiến hành trên 96 người chể biến thực phẩm tại bếp ăn tập thể của 32 bệnh viện tại Hà Nội. Kết quả của nghiên cứu này cho thấy tỷ lệ người chế biến thực phẩm có kiến thức chung về an toàn thực phẩm đạt 10,4\%. Tỷ lệ người chế biến thực phẩm có thực hành chung về an toàn vệ sinh thực phẩm (ATVSTP) đạt 55,2\%. Như vậy, tỷ lệ người chế biến thực phẩm có kiến thức và thực hành đạt về ATVSTP còn thấp.

Từ khóa: Vệ sinh thực phẩm, An toàn thực phẩm, bếp ăn tập thể, bệnh viện.

\section{SUMMARY \\ KNOWLEDGE, PRACTICES OF FOOD SAFETY AND HYGIENE OF FOOD HANDLERS AT THE COMMUNAL KITCHENS OF HOPITALS IN HA NOI IN 2020}

A cross-sectional study was conducted on 96 food processors in the communal kitchens of 32 hospitals in

\footnotetext{
${ }^{1}$ Viện Đào tạo YHDP \& YTCC, Đại học Y Hà Nội

${ }^{2}$ Chi cục An toàn vệ sinh thực phẩm Hà Nội

Chịu trách nhiệm chính: Nguyễn Thị Thu Hà

Email: hanguyen1595@gmail.com

Ngày nhân bài: 12.01.2021

Ngày phản biên khoa học: 16.3.2021

Ngày duyệt bài: 25.3.2021
}

$\mathrm{Ha}$ Noi. The results of this study showed that the proportion of food workers with general knowledge about food safety reached $10.4 \%$. The proportion of correct common food safety and hygiene practices of people personally dealing with food was $55.2 \%$. Thus, the proportion of food handlers who have both knowledge and practice about food safety is low.

Keywords; food hygiene, food safety, communal kitchen, hospital.

\section{I. ĐặT VẤN ĐỀ}

Ngộ độc thực phẩm là vấn đề sức khỏe cộng đồng phổ biến và quan trọng trên toàn thế giới. Tổ chức Y tế Thế giới (WHO) ước tính có tới $30 \%$ dân số mắc các bệnh do thực phẩm gây ra ở các nước phát triển và gây ra 2 triệu ca tử vong mỗi năm ở các nước đang phát triển[1].

Tại Việt Nam, theo số liệu của Tổng cục Thống kê cho thấy, năm 2017 ghi nhận 111 vụ ngộ độc thực phẩm, làm 3374 người bị ngộ độc và có 22 người đã bị tử vong. Trong 6 tháng đầu năm 2018, cả nước xảy ra 44 vụ ngộ độc thực phẩm, làm 1.207 người bị ngộ độc và 7 trường hợp tử vong[2].

Trong đó, bếp ăn tập thể (BĂTT) là nơi có nguy cơ cao dẫn đến ngộ độc thực phẩm (90\%) do số lượng suất ăn lớn nên quá trình chế biến 
bảo quản và vận chuyển đã ảnh hưởng đến chất lượng của các suất ăn[3]. Từ năm 2011 Bộ Y tế ban hành Thông tư 08/2011/TT-BYT trong đó có qui định về việc thành lập các BĂTT cung cấp suất ăn cho bênh nhân tại khoa dinh dưỡng của các bệnh viện. Cho đến nay rất nhiều bệnh viện đã có khoa dinh dưỡng tiết chế và xầy dựng được các bếp ăn bênh viên.

Vì vậy, bên cạnh việc đảm bảo điều kiện an toàn vệ sinh thực phẩm (ATVSTP) thì việc đảm bảo kiển thức và thực hành của người chế biến thực phẩm (CBTP) tại BĂTT bệnh viện đóng vai trò vô cùng quan trong ảnh hưởng đến tình trạng sức khỏe bệnh tật của người bệnh đặc biệt là tại Hà Nội - một trong những nơi tập trung các bệnh viện tuyến Trung ương, các bệnh viện và cớ sở y tế uy tín với nhiều khuyên khoa khác nhau. Bên cạnh đó, hiện nay vẫn chưa có nghiên cứu nào tìm hiểu thực trạng về kiến thức thực hành về ATVSTP của người CBTP tại bếp ăn của bệnh viện. Do vậy, chúng tôi tiến hành nghiên cứu với mục tiêu 'Mô tả kiến thức, thực hành về vê sinh an toàn thực phẩm của người CBTP tại BÁTT một số bệnh viện tại Hà Nội năm 2020'.

\section{II. ĐỐI TƯỢNG VÀ PHƯƠNG PHÁP NGHIÊN CỨU}

2.1. Đối tượng nghiên cứu. Người CBTP làm việc tại BĂTT thuộc khoa dinh dưỡng của 32 bệnh viện tại Hà Nội.

\subsection{Phương pháp nghiên cứu}

2.2.1. Thiết kế nghiên cứu: Mô tả cắt ngang

2.2.2. Cỡ mẫu và chọn mẫu: Tại mỗi bệnh viện chọn chủ đích 3 người CBTP với tiêu chí là người tham gia trực tiếp tại các khâu trọng yếu của quá trình CBTP: sơ chế, nấu nướng, chia thức ăn vào nghiên cứu. Như vậy sẽ có tổng cộng 96 người CBTP được lựa chọn tham gia nghiên cứu.

2.2.3. Thời gian và địa điểm nghiên cứu: Từ tháng 8/2020 đến 3/2021 tại BATTT của 32 bệnh viện tại Hà Nội.

2.2.4. Phương pháp thu thập số liệu: sử dụng bộ câu hỏi đánh giá kiến thức, thực hành thông qua phỏng vấn trực tiếp và quan sát kỹ năng thực hành của người CBTP; bộ câu hỏi được tham khảo theo Quyết định số 37/QĐATTP ngày 02/2/2015 của Cục ATTP, Bộ $Y$ tế về việc "Ban hành tài liệu tập huấn kiến thức ATTP và bộ câu hỏi đánh giá kiến thức ATTP của chủ cơ sở và người trực tiếp chế biến, kinh doanh dịch vụ ăn uống và đáp án trả lời", bộ câu hỏi được thử nghiệm trước khi tiến hành nghiên cứu.

Đánh giá kiến thức ATTP của người CBTP gồm 24 câu hỏi: Với câu hỏi một lựa chọn: trả lời đúng được 1 điểm, trả lời sai không được điểm.
Với câu hỏi nhiêu lựa chọn: mỗi ý trả lời đúng được 1 điểm, sai không được điểm. Điểm tối đa cho 24 câu hỏi là 70 điểm, người CBTP được đánh giá là đạt yêu cầu về kiến thức ATVSTP khi đạt tối thiểu $80 \%$ số điểm, tương ứng với $70 \mathrm{x}$ $0,8=56$ điểm.

Đánh giá thực hành chung về ATTP gồm 18 câu, mỗi câu tương ứng với mức điểm nhất định. Dựa vào phần trả lời và quan sát thực tế các câu hỏi để tính điểm, điểm tối đa cho phần trả lời 18 câu là 29 điểm. Tổng điểm thực hành $\geq 80 \%$ được đánh giá là thực hành đạt về ATTP, tương ứng với $29 \times 0,8=23$ điểm.

2.3. Xử lý số liệu: Số liệu được nhập, làm sạch bằng phần mềm Epidata 3.1 và xử lý bằng phần mềm SPSS 20.

2.4. Đạo đức nghiên cứu. Nghiên cứu hoàn toàn được sự đồng ý của các trưởng khoa Dinh dưỡng các bệnh viện nghiên cứu. Đối tượng nghiên cứu được giải thích rõ ràng về mục đích, ý nghĩa của nghiên cứu và tự nguyện tham gia nghiên cứu. Toàn bộ thông tin mà đối tượng cung cấp chỉ sử dụng cho mục đích nghiên cứu, không sử dụng cho mục đích khác và được bảo mật tuyệt đối.

\section{KẾT QUẢ NGHIÊN CỨU}

Bảng 1. Thông tin chung của đôi tượng nghiên cứu (n=96)

\begin{tabular}{|c|c|c|c|}
\hline Chỉ số & Thông tin & $\begin{array}{l}\text { Số lượng } \\
\text { (n) }\end{array}$ & $\begin{array}{l}\text { Tỷ lệ } \\
(\%)\end{array}$ \\
\hline \multirow{2}{*}{ Giới tính } & Nam & 46 & 47,9 \\
\hline & Nữ & 50 & 52,1 \\
\hline \multirow{5}{*}{$\begin{array}{l}\text { Nhóm } \\
\text { tuổi }\end{array}$} & $\leq 20$ tuối & 6 & 6,3 \\
\hline & $21-30$ tuối & 43 & 44,8 \\
\hline & $31-40$ tuối & 26 & 27,1 \\
\hline & $41-50$ tuối & 17 & 17,7 \\
\hline & Trên 50 tuối & 4 & 4,2 \\
\hline \multirow{5}{*}{$\begin{array}{l}\text { Trình độ } \\
\text { học vân }\end{array}$} & Tiếu học & 4 & 4,2 \\
\hline & THCS & 29 & 30,2 \\
\hline & THPT & 42 & 43,8 \\
\hline & Trung cấp & 9 & 9,4 \\
\hline & Cao đắng, đại học & 12 & 12,5 \\
\hline \multirow{4}{*}{\begin{tabular}{|} 
Trình độ \\
về chế \\
biến thực \\
phẩm
\end{tabular}} & Sơ cấp nâu ăn & 13 & 13,5 \\
\hline & Trung cấp nấu ăn & 23 & 24,0 \\
\hline & Cao đằng nấu ăn & 10 & 10,4 \\
\hline & Không có bằng cấp & 50 & 52,1 \\
\hline \multirow{4}{*}{ Tuổi nghề } & $\begin{array}{c}\text { Từ } 6 \text { tháng đến } \\
<1 \text { năm }\end{array}$ & 35 & 36,5 \\
\hline & $1-5$ năm & 40 & 41,7 \\
\hline & 6 - 10 năm & 7 & 7,3 \\
\hline & $11-20$ năm & 14 & 14,6 \\
\hline
\end{tabular}

Bảng 1 cho thấy nữ giới chiếm tỷ lệ cao hơn so với nam giới $(52,1 \%$ và $47,9 \%)$. Phần lớn tuổi của những người CBTP nằm trong khoảng từ 21 
- 30 tuổi $(44,8 \%)$, những người trên 50 tuổi và $\leq 20$ tuổi chiếm tỳ lệ rất thấp lần lượt là 4,2\% và $6,3 \%$; trình độ học vấn đa phần tốt nghiệp THPT trở lên với $65,7 \%$; thấp nhất là tiểu học $(4,2 \%)$. Về trình độ chuyên môn của người CBTP cho thây có $52,1 \%$ người CBTP không được đào tạo về nấu ăn. Có $78,2 \%$ số người CBTP có thời gian làm nghề dưới 5 năm; thời gian hành nghề CBTP từ 11-20 năm chiếm 14,6\% tổng số đối tượng.

Bảng 2. Kiến thức về chung về an toàn vệ sinh thực phẩm của người chế biến

\begin{tabular}{|c|c|c|c|}
\hline & & Số lượng (n) & Tỷ lệ (\%) \\
\hline \multirow{4}{*}{$\begin{array}{l}\text { Khoảng cách bàn sơ } \\
\text { chế với mặt sàn }\end{array}$} & $30 \mathrm{~cm}$ & 1 & 1,0 \\
\hline & $60 \mathrm{~cm}$ & 23 & 24,0 \\
\hline & $90 \mathrm{~cm}$ & 20 & 20,8 \\
\hline & Không biết & 52 & 54,2 \\
\hline \multirow{5}{*}{ Thiết kế bếp ăn } & Thiết kế chế biến theo một chiều & 64 & 66,7 \\
\hline & Các cửa, ô thoáng có kính hoặc lưới & 65 & 67,7 \\
\hline & Nền, tường, trần khu bếp sáng màu & 66 & 68,8 \\
\hline & Phân khu riêng biệt thực phấm sồng, chín & 89 & 92,7 \\
\hline & Cống thoát nước kín hay hở đều được & 3 & 3,1 \\
\hline \multirow{3}{*}{$\begin{array}{c}\text { Vật liếu dụng cụ chế } \\
\text { biến, chứa đựng } \\
\text { thực phẩm }\end{array}$} & Inox & 92 & 95,8 \\
\hline & Gốm, sứ, thủy tinh & 11 & 11,5 \\
\hline & Các loại nhựa & 15 & 15,6 \\
\hline \multirow{3}{*}{$\begin{array}{c}\text { Tác dụng của nước } \\
\text { sạch }\end{array}$} & Phòng lây nhiêm mầm bệnh, chất độc vào thực phẩm & 39 & 40,6 \\
\hline & Phòng được sự sinh sản và phát triển của mầm bệnh & 30 & 31,3 \\
\hline & Cả 2 ý trên đều đúng & 27 & 28,1 \\
\hline \multirow{5}{*}{$\begin{array}{l}\text { Người CBTP cần } \\
\text { phải rửa tay }\end{array}$} & Trước khi CBTP & 43 & 44,8 \\
\hline & Sau khi đi vệ sinh & 68 & 70,8 \\
\hline & Sau khi tiếp xúc với rác, ngoáy tai, mũi, gãi ngứa & 73 & 76,0 \\
\hline & $\begin{array}{l}\text { Sau khi tiếp xúc với lông súc vật hoặc bề mặt } \\
\text { không đảm bảo vệ sinh }\end{array}$ & 65 & 67,7 \\
\hline & Tất cả ý trên đúng & 22 & 22,9 \\
\hline
\end{tabular}

Bảng 2 cho thấy có tới $54,2 \%$ người CBTP không biết về khoảng cách bàn sơ chế so với mặt sàn. Có hơn $90 \%$ người CBTP cho rằng cần phân khu riêng biệt thực phẩm sống - chín $(92,7 \%)$. Tuy nhiên chỉ có $66,7 \%$ người CBTP cho biết BĂTT thiết kế theo nguyên tắc 1 chiều; cửa, ô thoáng có kính hoặc lưới và nền tường, trần khu vực bếp sáng màu lần lượt với $67,7 \%$ và $68,8 \%$. Vẫn còn $3,1 \%$ người $C B T P$ cho rằng cống thoát nước của khu chế biến kín hay hở đều được. $15,6 \%$ cho rằng dụng cụ chế biến có thể dùng các loại nhựa. Chỉ có $28,1 \%$ người CBTP hiểu đúng về tác dụng của việc sử dụng nước sạch trong CBTP. Khi được hỏi về việc rửa tay của người CBTP, trên $70 \%$ các đối tượng cho rằng cần phải rửa tay sau khi đi vệ sinh, sau khi tiếp xúc với rác và với lông súc vật. Tuy nhiên, chỉ có $43 / 96$ đối tượng $(44,8 \%)$ cho rằng cần phải rửa tay trước khi CBTP.

Bảng 3. Thức hành chung về an toàn thực phẩm của người chế biến

\begin{tabular}{|c|c|c|c|}
\hline $\begin{array}{c}\text { Thực hành } \\
\text { chung }\end{array}$ & Chỉ số & $\begin{array}{c}\text { Số lượng } \\
\text { (n) }\end{array}$ & $\begin{array}{c}\text { Tỷ lệ } \\
\text { (\%) }\end{array}$ \\
\hline $\begin{array}{c}\text { Nơi chứa } \\
\text { đựng rác, }\end{array}$ & $\begin{array}{c}\text { Thùng rác có nắp } \\
\text { đậy kín }\end{array}$ & 58 & 60,4 \\
\hline
\end{tabular}

\begin{tabular}{|c|c|c|c|}
\hline \multirow[t]{3}{*}{ chất thải } & Túi nilon & 41 & 42,7 \\
\hline & $\begin{array}{c}\text { Đế dưới đất nền } \\
\text { nhà bếp }\end{array}$ & 5 & 5,2 \\
\hline & Đế ở nơi khác & 2 & 2,1 \\
\hline \multirow{2}{*}{$\begin{array}{l}\text { Dao thớt } \\
\text { riêng biệt }\end{array}$} & Có & 88 & 91,7 \\
\hline & Không & 8 & 8,3 \\
\hline \multirow{2}{*}{$\begin{array}{l}\text { Thực phẩm } \\
\text { được bảo } \\
\text { quản lưu giữ }\end{array}$} & Tủ lạnh & 93 & 96,9 \\
\hline & $\begin{array}{l}\text { Đế ngoài, không } \\
\text { lưu }\end{array}$ & 3 & 3,1 \\
\hline \multirow{2}{*}{$\begin{array}{l}\text { Nơi sơ chế } \\
\text { TP }\end{array}$} & $\begin{array}{l}\text { Đế trực tiếp trên } \\
\text { nền nhà bếp }\end{array}$ & 24 & 25,0 \\
\hline & $\begin{array}{l}\text { Trên bàn cách } \\
\text { mặt đất > } 60 \mathrm{~cm}\end{array}$ & 72 & 75,0 \\
\hline \multirow{5}{*}{$\begin{array}{l}\text { Trang phục } \\
\text { sử dựng khi } \\
\text { chế biến TP }\end{array}$} & Mũ chụp tóc & 61 & 63,5 \\
\hline & Khấu trang & 28 & 29,2 \\
\hline & Găng tay & 30 & 31,3 \\
\hline & Tap dề & 70 & 72,9 \\
\hline & Quần áo bảo hô & 58 & 60,4 \\
\hline \multirow{2}{*}{$\begin{array}{l}\text { NCB dùng } \\
\text { tay trực } \\
\text { tiếp để bốc } \\
\text { thức ăn }\end{array}$} & Có & 18 & 18,8 \\
\hline & Không & 78 & 81,2 \\
\hline
\end{tabular}

Bảng 3 cho thây $60,4 \%$ cơ sở chứa đựng chất thải, rác thải và thùng rác có nắp đậy kín; tuy nhiên vẫn có $42,7 \%$ để rác ở túi nilong, 5,2\% để dưới nền nhà bếp và $2,1 \%$ để ở nơi khác. Bên 
canh đó, $96,9 \%$ số cơ sở khám sức khỏe tối thiểu 1 lần/năm cho người CBTP; 91,7\% số cơ sở sử dụng dao thớt riêng biệt sống, chín. hầu hết các cơ sở $(96,9 \%)$ thực phẩm được bảo quản, lưu giữ trong tủ lạnh. 75\% người CBTP sơ chế TP trên mặt bàn cách mă̆t đất $\geq 60 \mathrm{~cm}$. thây sử dụng tạp dề, mũ chụp tóc, quần áo bảo hộ lần lượt với $72,9 \% ; 63,5 \%$ và $60,4 \%$. Tuy nhiên, chỉ có $31,3 \%$ người CBTP có sứ dụng găng tay và $29,2 \%$ đối tượng có đeo khẩu trang. Bên cạnh đó, vẫn có $18,8 \%$ người CBTP dùng tay trực tiếp để bốc chia thức ăn chín.

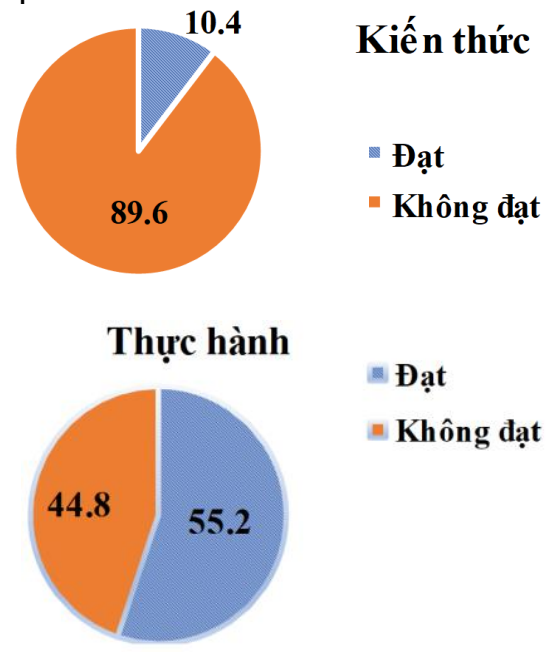

Biểu đồ 1. Tỷ lệ người chế biến đạt yêu cầu kiến thức và thực hành chung về an toàn vệ sinh thực phẩm $(n=96)$

Biểu đồ 1 cho thấy tỷ lệ người CBTP có kiến thức chung đạt yêu cầu về ATVSTP rất thấp $(10,4 \%)$. Bên cạnh đó, tỷ lệ người CBTP đạt yêu cầu về thực hành VSATTP tại BĂTT là $55,2 \%$.

\section{BÀN LUÂN}

Đối với kiến thức về ATVSTP của người CBTP tại BĂTT bệnh viện, chỉ có $24 \%$ biết về yêu cầu của bàn sở chế so với mặt sàn, $92,7 \%$ người CBTP cho rằng cần phân khu riêng biệt thực phẩm sống - chín, $66,7 \%$ người CBTP cho biết BĂTT thiết kế theo nguyên tắc 1 chiều. Tuy nhiên vẫn còn $3,1 \%$ người $\mathrm{CBTP}$ cho rằng cống thoát nước của khu chế biến kín hay hở đều được. Kết quả này cao hơn kết quả của nghiên cứu Lê Thị Hồng Ngọc tại bếp ăn mầm non với $50 \%$ có kiến thức về thiết kế bếp ăn 1 chiêu; $59,5 \%$ cống rãnh thoát nước phải che đậy kín[4]. Tuy nhiên lại thấp hơn kết quả của nghiên cứu Đặng Quang Tân tại trường tiểu học khi tỷ lệ có kiến thức đúng hầu hết đều trên 90\%[5].
Về vật liệu của dụng cụ chế biến, chứa đựng thực phẩm, vẫn có $15,6 \%$ cho rằng có thể dùng các loại nhựa. Đối với kiến thức về tác dung của nước sạch, chỉ có $28,1 \%$ người CBTP hiểu đúng về tác dụng của việc sử dụng nước sạch trong CBTP. Bên canhh đó, trên $70 \%$ các đối tượng cho rằng cần phải rửa tay sau khi đi vệ sinh, sau khi tiếp xúc với rác và với lông súc vật. Tuy nhiên, chỉ có $44,8 \%$ đối tượng cho rằng cần phải rửa tay trước khi CBTP. Kết quả này thấp hơn kết quả của nghiên cứu Lê Như Huỳnh với tỷ lê người CBTP tại các trường mầm non có kiến thức đúng về vật liệu chứa đựng thực phẩm và hiểu biết về vệ sinh tay đều trền $90 \%[6]$.

Đối với thực hành chung về ATVSTP của người $\mathrm{CB}, 60,4 \%$ cơ sở chứa đựng chất thải, rác thải và thùng rác có nắp đậy kín; tuy nhiên vẫn có $42,7 \%$ để rác ở túi nilong và $5,2 \%$ để dưới nền nhà bếp. Bên cạnh đó, $96,9 \%$ số cơ sở khám sức khỏe tối thiểu 1 lần/năm cho người CBTP; $91,7 \%$ số cơ sở sử dụng dao thớt riêng biệt sống, chín; $96,9 \%$ các bểp ăn có thực phẩm được bảo quản, lưu giữ trong tủ lanh và $75 \%$ người CBTP sơ chế TP trên mặt bàn cách mặt đất $\geq 60 \mathrm{~cm}$. Kết quả này đều thấp hơn kết quả của nghiên cứu Đố Ngọc Chi (2019) các trường tiểu học quận Nam Từ Liêm với $100 \%$ tỷ lệ đạt về thực hành bao gồm sơ chế cách mặt đất, dao thớt riêng biệt, $88,8 \%$ đựng rác và chất thải trong thùng rác[7].

Về việc sử dụng trang phục bảo hộ, tỷ lệ người CBTP sử dụng tạp dề, mũ chụp tóc, quần áo bảo hộ lần lượt với $72,9 \% ; 63,5 \%$ và $60,4 \%$. Tuy nhiên, chỉ có $31,3 \%$ người CBTP có sử dụng găng tay và $29,2 \%$ đối tượng có đeo khẩu trang. Kết quả này thấp hơn nghiên cứu của Lê Như Huỳnh với tỷ lệ thực hành đúng về đep tạp dề, đeo khẩu trang và đội mũ che tóc lần lượt $78,8 \% ; 81,2 \%$ và $77,5 \%[6]$.

Bên cạnh đó, vẫn có $18,8 \%$ người CBTP dùng tay trực tiếp để bốc chia thức ăn chín. Kết quả này cao hơn kết quả của Đặng Quang Tân tại các trường tiểu học tại Hà Nội với tỷ lệ là 11,2\%[5]

Kết quả nghiên cứu của chúng tôi cho thây, tỷ lệ đạt về kiến thức rất thấp $(10,4 \%)$, trong khi đó tỷ lề đạt về thực hành chiếm $55,2 \%$. Kết quả này thấp hơn kêt quả của nghiên cứu Lê Như Huỳnh về đánh giá BĂTT năm 2020 tại Mỹ Tho với tỷ lệ đạt về kiến thức và thực hành lần lượt là $74,6 \%$ và $85,4 \%[6]$, nghiên cứu của Đặng Quang Tân với tỷ lệ đạt $68,7 \%$ về kiến thức và $77,6 \%$ về thực hành tại các trường tiểu học[5].

Sự khác biệt này có thể lí giải bằng việc các BĂTT bệnh viện đều dưới sự quản lí và giám sát 
bởi khoa dinh dưỡng của bệnh viện vì vậy ý thức trong việc thực hành về ATTP của người CBTP sẽ tốt hơn so với kiến thức của họ. Tuy nhiên tỷ lệ thấp có thể do đối tượng nghiên cứu bao gồm cá những người CBTP tại các BĂTT bệnh viện tuyến quận, huyện. Bên cạnh đó, một số khoa dinh dưỡng mới được thành lập mây năm gần đây, số lượng cán bộ dinh dưỡng có trình độ chuyên môn đắc biệt là về ATTP còn han chế nên kiến thức về ATTP hay đào tạo nhân viên CBTP của bếp ăn về ATTP còn gặp nhiều khó khăn. Bên canh đó, các nghiên cứu trên đều tiến hành tại các trường mầm non, tiểu hoc, các khu doanh nghiệp đã có sự đầu tư, chú trọng và quan tâm từ nhiêu năm trước. Qua đó, cần có sự quan tâm hơn nữa về việc tập huấn kiến thức ATTP đối với cán bộ thuộc khoa dinh dưỡng và người CBTP tại các bệnh viện đồng thời tăng cường giám sát về ATVSTP nhẳm nâng cao chất lượng ATTP bếp ăn bệnh viện tại Hà Nội nói riêng và các bếp ăn bệnh viện trển toàn quốc nói chung.

\section{KẾT LUÂ̂N}

Tỷ lệ người chế biến thực phẩm có kiến thức và thực hành về an toàn vệ sinh thực phẩm tại bếp ăn một số bệnh viện tại Hà Nội còn thấp, với $10,4 \%$ người chế biến đạt yêu cầu về kiến thức và $55,2 \%$ đạt yêu cầu về thực hành.

\section{TÀI LIẸU THAM KHẢO}

1. Legesse Eshetu, Regea Dabsu, Geletta Tadele (2019). Prevalence of intestinal parasites and its risk factors among food handlers in food services in Nekemte town, west Oromia, Ethiopia. Research and reports in tropical medicine, 10, 25.

2. Thu Hòa (2018). Đẩy mạnh phát triển chuỗi cung ứng thực phẩm an toàn. Tap chí Con số và Sự kiên, tổng cục thống kê, $7 / 2018$ (532),

3. Bô̂ Y tế (2001). Quyết định số $4128 / 2001 / \mathrm{Q} Đ-$ BŶT ngày 03/10/2001 của Bô trưởng Bộ $Y$ tế về việc ban hành "Quy định về điêuu kiện bảo đảm An toàn vệ sinh thực phẩm các nhà ăn, bếp ăn tập thể và cơ sở kinh doanh chế biến suất ăn sằn".

4. Trinh Bảo Ngoc, Lê Thi Hồng Ngọc, Nguyễn Thi Thu Liễu (2020). Kiến thức, thực hành vê vệ sinh an toàn thực phẩm của người chế biến thực phẩm tai bếp ăn trường mầm non huyên Nam Sách, Hải Dương năm 2019. Tạp chí nghiên cứu y hoc, 5 (129), 240-246.

5. Đăng Quang Tân (2019). "Thực trang an toàn vể sinh thực phẩm tại bếp ăn tập thể của một số trường tiểu hoc thành phố Hà Nôi năm 2018" , Luân văn thac sỹ, Đai hoc Y Hà Nôi, Hà Nôi.

6. Lê Như Huỳnh (2020). Kiến thức, thực hành về an toàn thực phẩm của người trực tiếp chế biến tại bếp ăn tập thể trường học trên địa bàn thành phố Mỹ Tho năm 2020. Tạp chí Y học Việt Nam, 2 (493), 164-169.

7. Đố Ngoc Chi (2019). "Điều kiện an toàn thực phẩm và một số yếu tố liên quañ đến kiến thứcthực hành an toàn thực phẩm của người chế biến tại bếp ăn các trường tiểu học quâan Nam Từ Liêm, Hià Nối, năm 2019", Luận văn thạc sĩ y tế công cộng, Đại học Thăng Long, Hà Nội.

\section{MÔ HİNH BỆNH TẬT CỦA NGƯỜI BỆNH ĐIỀU TRI NộI TRÚ TẠI BỆNH VIỆN NHI TỈNH THANH HOÁ NĂM 2017-2019}

\section{TÓM TẮT}

Mục tiêu: Mô tả cơ cấu bệnh tật của người bệnh điêu tri nôi trú tai bênh viên Nhi, tỉnh Thanh Hoá 3 năm từ 2017 đến 2019. Phương pháp: Nghiên cứu mô tả cắt ngang, qua thống kê bênh tật của người bệnh điêu trị nội trú trong thời gian 3 năm nghiên cứu. Tổng số 152.451 hồ sơ của người bênh điều trị nội trú đã̃ được chọn cho nghiên cứu. Sử dụng bảng phân loại Quốc tế bệnh tật lần thứ 10 (ICD10) để thống kể mô hình bệnh tật. Kết quả: Trong 3 năm, các nhóm bệnh chiếm tỷ lể cao nhất theo ICD10 gồm: Bệnh hệ hố hấp chiếm $41,4 \%$, trong đó viêm phổi

${ }^{1}$ Bệnh viện Nhi tỉnh Thanh Hoá.

2Viện Đào tạo $Y$ học dự phòng và Y tế công cộng, trường Đai họ Y Hà Nối.

Chịu trách nhiệm chính: Phùng Đức Toàn

Email: toanphung6685@gmail.com

Ngày nhận bài: 20.01.2021

Ngày phản biên khoa học: 16.3.2021

Ngày duyệt bài: 26.3.2021
Phùng Đức Toàn', Phạm Bích Diệp ${ }^{2}$, Nguyễn Văn Hiến ${ }^{2}$

(J18) mắc cao nhất $(44,1 \%)$; Bệnh hệ tiêu hoá chiếm $16,7 \%$, trong đó bệnh đường ruột do vi rút, tác nhân xác định khác (A08), mắc cao nhất $(28,8 \%)$; Bệnh nhiễm khuẩn và ký sinh vật chiếm $6,4 \%$, trong đó bệnh vàng da sơ sinh ( $\mathrm{P} 59)$ mắc cao nhất $(40,7 \%)$. Nểu phân loại theo 3 nhóm bệnh thì nhóm bệnh chiếm tỷ lệ cào nhất là bệnh lây nhiễm $66,15 \%$, tiếp đến là bệnh không lây nhiễm $27,5 \%$, thấp nhất là nhóm tai nan, ngô đôc chấn thương $6,4 \%$. Chúng tôi khuyến nghị bệnh viện Nhi tỉnh Thanh hoá nên dựa vào mô hình bệnh tật này, chủ động lập kế hoạch giường bênhh, nguồn lực, để cung cấp dịch vụ phù hợp với nhu cầu của người bệnh điều trị tại bênh viện.

Tư khóa: Mô hình bệnh tật; Người bệnh nội trú; Phân loại quốc tế bệnh tật lần thứ 10 (ICD10).

\section{SUMMARY \\ DISEASE PATTERN OF INPATIENTS AT \\ PEDIATRIC HOSPITAL OF THANH HOA PROVINCE FROM 2017 TO 2019}

Objective: To discribe the disease pattern of the inpatient at Pediatric Hospital of Thanh Hoa province 